\title{
Preparation, Characterization and Compatibility Studies of Naproxen Loaded Microspheres of Cellulosic and Polymethacrylic Polymeric Blend
}

\author{
Sharmin Akhter ${ }^{1}$, Shovan Paul ${ }^{2}$, Ikramul Hasan ${ }^{2}$, Navid J ubaer Ayon ${ }^{2}$, \\ Syed Shabbir Haider ${ }^{2}$ and Md. Selim Reza \\ ${ }^{1}$ Department of Pharmacy, University of Asia Pacific, Dhanmondi, Dhaka-1209, Bangladesh
${ }^{2}$ Department of Pharmaceutical Technology, Faculty of Pharmacy, University of Dhaka, \\ Dhaka-1000, Bangladesh.
}

\begin{abstract}
Naproxen, a well-known non-steroidal anti-inflammatory drug was encapsulated with cellulosic and polymethacrylic polymers to provide sustained action and to minimize gastro esophageal side effects by avoiding the release of drug in the upper gastrointestinal tract. Emulsification-solvent evaporation technique using Ethyl Cellulose, Eudragit RSPO and their combination as release retardant was the method of choice. The formulations were prepared by keeping the amount of drug fixed to $1 \mathrm{~g}$ and the total amount of polymer fixed to $1 \mathrm{~g}$ in which Ethyl Cellulose and Eudragit RSPO were used in varying combination. In-vitro drug release was studied in a paddle type dissolution apparatus (USP type II) for eight hours in phosphate buffer having $\mathrm{pH}$ 7.4. After 8 hours, the release of drug was $86.20 \%$ for F6 which contains equal amount of Ethyl Cellulose and Eudragit RS PO and $71.57 \%$ for F7 which contains only Eudragit RSPO. The release mechanisms were explored and explained with zero order, first order, Higuchi, Korsmeyer-Peppas and Hixson Crowell models. The correlation-coefficient values of the trend lines of the graphs showed that the formulations were best fitted with Korsmeyer-Peppas release pattern. Microspheres surface morphological study was done by Scanning Electron Microscopy (SEM). Drug polymer incompatibility studies were performed by Differential Scanning Calorimetry (DSC) and Fourier Transform Infrared Spectroscopy (FTIR). The absence of endothermic melting peak of Naproxen in DSC thermogram revealed that the drug might be dispersed in the polymer as solid solution or in a metastable molecular dispersion. But the chemical integrity of Naproxen was not changed or destroyed within the microsphere which was confirmed by FTIR report.
\end{abstract}

Key words: Ethyl Cellulose, Eudragit RSPO, Naproxen, Microsphere, Emulsification-Solvent evaporation method.

\section{INTRODUCTION}

Microspheres are defined as homogenous, monolithic particles in the size range of $1-1000 \mu \mathrm{m}$ and are widely used as a drug carrier for sustained release action. This delivery system is used to achieve controlled drug delivery, improved bioavailability, stability and targeted drug delivery to specific sites. Microspheres also offer other advantages such as limiting fluctuation within the therapeutic range, reduction in the side effects,

Correspondence to: Md. Selim Reza

Tel: +880-2-8612069, Fax: +880-28615583

E-mail: selim.du@gmail.com

Dhaka Univ. J. Pharm. Sci. 12(1): 11-21, 2013 (June) decreased dose frequency and improved patient compliance. This technology is mainly used for the purpose of protection, controlled release, and incompatibility of the core materials. ${ }^{1,2}$ The popular method for encapsulation of drugs within water soluble polymers is the emulsion solvent evaporation technique. This technique offers several advantages and is preferable to other preparation methods such as spray drying, sonication, ionotropic gelation and homogenization because it requires only mild condition such as ambient temperature and constant stirring. Thus a stable emulsion can be formed without compromising the activity of the drugs. Both 
Ethyl Cellulose and Eudragit RSPO are biocompatible polymer. ${ }^{3}$ Films prepared by Eudragit RSPO are only slightly permeable to water. ${ }^{4}$ Both the polymers are used for tablet coating as well as in the microencapsulation of various drugs.

Naproxen is a nonsteroidal anti-inflammatory drug (NSAID), mainly used in osteoarthritis, rheumatoid arthritis, and ankylosing spondylitis. Naproxen is a suitable candidate for oral sustained release dosage form with a short half-life 1-3 hours. The usual dose of Naproxen is $250 \mathrm{mg}$ or $500 \mathrm{mg}$ three times a day. Naproxen is extensively bound to plasma albumin, so it is more rational to deliver this drug in sustained-release dosage form. ${ }^{5}$ Thus Naproxen is a suitable candidate for sustained delivery system. In order to establish and optimize the suitability of Naproxen to formulate as microspheres, the factors affecting particle size, drug loading, drug incorporation efficiency and drug release behavior of the Naproxen microspheres were investigated in this study. The compatibility of Naproxen with the excipients was studied by FTIR and DSC.

\section{MATERIALS AND METHODS}

The following materials were obtained from the indicated suppliers and used as received:

Naproxen (ACI Pharmaceuticals), Ethyl Cellulose 14 cps (Colorcon), Eudragit RSPO (Evonik Industries), Dichloromethane (MERK, Germany), Ethanol (Merk, Germany), Span 80 (MERK, Germany), n-hexane (MERK, Germany), liquid paraffin (MERK, Germany), Di Sodium Hydrogen Phosphate (MERK, Germany) and Sodium Di-hydrogen Phosphate (MERK, Germany).
Preparation of Naproxen microspheres by emulsification solvent evaporation method using Ethyl Cellulose and Eudragit-RSPO. The method of preparation of the microspheres was based on the "emulsification solvent evaporation technique". Ethanol and dichloromethane were used as solvent and span 80 was used as emulsifier. The polymers (Ethyl Cellulose or Eudragit RSPO or Combination of both) were dissolved in $20 \mathrm{ml}$ dichloromethane by continuous stirring with a clean glass rod until a clear solution was formed. Then required amount of the drug was added followed by addition of $5 \mathrm{ml}$ ethanol. The solution was again stirred until a clear solution or dispersion was formed. The internal phase was thus prepared. For the formation of external phase, $100 \mathrm{ml}$ liquid paraffin containing $1 \mathrm{ml}$ span 80 was taken in preparatory vessel (500 $\mathrm{ml}$ beaker). RPM was set at 2500. The internal phase was poured drop by drop to the external phase after continuous stirring 5 minutes. After adding the internal phase, the stirring was continued until hard, uniformed round shaped microsphere was formed (Microspheres formation required approximately 3 hours). The container was then kept static to allow the microsphere for settling down. Serial washing was carried out with n-hexane. Then the microspheres were spread over a filter paper and left for natural drying in a desiccator. The RPM was kept fixed during the whole procedure. After drying, the microsphere were kept in a $10 \mathrm{ml}$ vial with proper identification and preserved in the desiccator. Here all the factors were kept constant except the amount of the polymer, Ethyl Cellulose and Eudragit RSPO. The total amount of drug and polymer was fixed at $2000 \mathrm{mg}$.

Table 1. Formulation of Naproxen microspheres using Ethyl Cellulose and Eudragit RSPO.

\begin{tabular}{lccccccc}
\hline Ingredients & $\mathrm{F} 1$ & $\mathrm{~F} 2$ & $\mathrm{~F} 3$ & $\mathrm{~F} 4$ & $\mathrm{~F} 5$ & $\mathrm{~F} 6$ & $\mathrm{~F} 7$ \\
Drug $(\mathrm{g})$ & 1 & 1 & 1 & 1 & 1 & 1 & 1 \\
Ethyl Cellulose $(\mathrm{g})$ & 0.1 & 0.2 & 0.3 & 0.4 & 0.5 & 1.0 & 0 \\
EU-RSPO $(\mathrm{g})$ & 0.9 & 0.8 & 0.7 & 0.6 & 0.5 & 0 & 1 \\
Ethanol $(\mathrm{ml})$ & 15 & 15 & 15 & 15 & 15 & 15 & 15 \\
DCM $(\mathrm{ml})$ & 5 & 5 & 5 & 5 & 5 & 5 & 5 \\
Span 80 & $1 \%$ & $1 \%$ & $1 \%$ & $1 \%$ & $1 \%$ & $1 \%$ & $1 \%$ \\
Paraffin $(\mathrm{ml})$ & & & & up to $100 \mathrm{ml}$ & & & \\
\hline
\end{tabular}

Particle size analysis and scanning electron microscope (SEM) study. Particle size of the microspheres was analyzed by Partica $^{\circledR}$. The microspheres were dispersed in $10 \%$ Tween 80 
solution and then sonicated. The mean particle size, median particle size, mode particle size, standard deviation etc were calculated.

The surface morphology and appearance of the microspheres were examined by scanning electron microscopy. The microspheres from the optimized batch were mounted on the SEM sample stab (aluminum stabs) which were coated with a double sided sticking tape, sealed and finally coated with gold $\left(200 \mathrm{~A}^{\circ}\right)$ under reduced pressure (0.001 torr) for 15 minutes using ion sputtering device. The gold coated samples were scanned using scanning electron microscope (s-3400N, Hitachi) under different magnification and photomicrographs of suitable magnification were dried completely before examination.

Drug loading $=\left(\frac{\mathrm{M}_{\text {actual }}}{\text { Wight quantity of powder of microsphere }} \times 100\right) \%$

Drug incorporation efficiency $=\left(\frac{M_{\text {actual }}}{M_{\text {theoretical }}} \times 100\right) \%$

Here, $\mathrm{M}_{\text {actual }}$ is the Naproxen content in weighed quantity of powder of microparticles and $\mathrm{M}_{\text {theoretical }}$ is the amount of Naproxen in microparticles calculated from the quantity added in the fabrication process.

In vitro dissolution study of microspheres containing naproxen in phosphate buffer (pH 7.4). In vitro dissolution study was performed in a paddle type (Type II) Dissolution Apparatus. $100 \mathrm{mg}$ of microsphere was taken from each batch of formulation for dissolution purpose. Phosphate buffer of $\mathrm{pH} 7.4$ was used as dissolution media, paddle speed was set at $50 \mathrm{rpm}$ and temperature was fixed at $37^{\circ} \mathrm{C}$. The fixed amount of microsphere from each batch was weighed and transferred in each dissolution basket.

The dissolution process was carried out for 8 hours and $5 \mathrm{ml}$ dissolution sample from each dissolution media was withdrawn at a predetermined intervals of 15 minutes, 30 minutes, 1 hour, 2 hour, 3 hour, 4 hour, 5 hour, 6 hour, 7 hour and 8 hour. Each and every time $5 \mathrm{~m} 1$ of dissolution sample was compensated by fresh $5 \mathrm{ml}$ phosphate buffer $(\mathrm{pH}$ 7.4).
Determination of drug loading and drug incorporation efficiency. $50 \mathrm{mg}$ microspheres were taken in a mortar and triturated properly until fine powder was formed. $20 \mathrm{mg}$ fine powder was taken in a screw cap test tube. $5 \mathrm{ml}$ ethanol was added with the powdered microsphere and was vortexed for 10 minutes. Then few ml phosphate buffer $(\mathrm{pH}$ 7.4) was added and again vortexed for 15 minutes. Then the solution was taken in $100 \mathrm{ml}$ volumetric flask by filtering. The volume of the solution adjusted to 100 $\mathrm{ml}$ with the buffer solution. The absorbance was taken at $271 \mathrm{~nm}$. Using the absorbance value, the amount of naproxen entrapped was determined with the help of standard curve. The drug loading and incorporation efficiency were calculated by using Eqs.1 and 2, respectively. 
Differential scanning calorimetric analysis. Differential Scanning Calorimetry (DSC) analysis was undertaken to characterize the changes, if any, during thermal exposure of the samples. The test was carried out using thermal analysis system (Shimadzu, DSC-60). Calibration with the standard (aluminium) were undertaken prior to subjecting the samples for study (between $30-300^{\circ} \mathrm{C}$ ), which were heated at $10^{\circ} \mathrm{C} / \mathrm{min}$ in an aluminium pan under a nitrogen atmosphere while using an empty pan as the reference in this instrument. The instrument automatically calculated onsets of melting point and enthalpy of fusion.

\section{RESULTS AND DISCUSSION}

Release kinetics of naproxen from microspheres. To find the release profile, dissolution of all the microspheres was carried out in phosphate buffer at $\mathrm{pH} 7.4$ for 8 hours at $50 \mathrm{rpm}$ and the release rate was calculated. Analysis of the release profile of Naproxen from the microspheres shows that the initial burst release of Naproxen increases with the increase of ethyl cellulose content. It is due to $\mathrm{pH}$ independent and more release retardant nature of Eudragit RSPO compared to Ethyl Cellulose (14cps). The release pattern also found to be changed with the changes of polymer ratio. So, the release rate of Naproxen from the microsphere can be modulated by adjusting the polymeric ratio.

From Table 3, it is observed that F6 and F7 both are fitted to Korsmeyer - Peppas model $^{6}$ and F7 secondarily follows Higuchi model ${ }^{7}$. The values of release exponent (n) for the batches F6 and F7 are 0.112 and 0.3 , respectively. Both values are below 0.45 and the $\mathrm{n}$ value of $\mathrm{F} 7$ is higher than F6. The values indicate that the drug was released from the formulation by following Fickian release mechanism more specifically diffusion controlled release mechanism. F1 to F5 is best fitted to Korsmeyer Peppas model. The values of release exponent (n) of all the formulation are below 0.45 and the value of $n$ is reduced with the increase concentration of ethyl cellulose. These values indicate that the drug was released from the formulation by following Fickian release pattern more specifically diffusion controlled release mechanism which means the zero order was changed over time. Both ethyl cellulose and Eudragit RSPO are biocompatible polymers. The ethyl cellulose is hydrophobic in nature and the Eudragit $\mathrm{RSPO}$ is $\mathrm{pH}$ independent in nature. The presence of quaternary ammonium group on Eudragit RSPO controls the extent of water uptake, swelling and permeability of water. ${ }^{8}$ Because of the individual properties of these polymers, they can be combined in various proportions to customize the desired release.

Effect of acidic media on the release dinetics of naproxen from the ethyl cellulose, Eudragit RSPO and combination of ethyl cellulose and Eudragit RSPO microspheres. This experiment was carried out to show the release pattern of Naproxen from the microsphere in the acidic media. $0.1 \mathrm{~N} \mathrm{HCl}$ was used as a dissolution media at $50 \mathrm{rpm}$. The experiment was carried out for two hours. Maximum

Table 2. Cumulative percent of release of different formulations in different time interval.

\begin{tabular}{cccccccc}
\hline Time (hr) & F1 & F2 & F3 & F4 & F5 & F6 & F7 \\
0 & 0 & 0 & 0 & 0 & 0 & 0 & 0 \\
\hline 0.25 & 32.74453 & 35.80543 & 44.78467 & 47.33625 & 51.70335 & 52.93273 & 25.04051 \\
0.5 & 45.07512 & 47.46449 & 51.2828 & 57.20025 & 61.8334 & 66.66178 & 29.23069 \\
1 & 52.42298 & 54.14922 & 54.99104 & 61.93304 & 67.81899 & 69.02919 & 34.87498 \\
2 & 63.22571 & 58.43711 & 59.77951 & 63.90607 & 70.91332 & 71.38362 & 40.27558 \\
3 & 68.83971 & 62.33686 & 63.06933 & 66.2082 & 72.47747 & 74.04527 & 48.56828 \\
4 & 72.72544 & 67.0603 & 69.76048 & 69.20904 & 73.67864 & 75.69979 & 53.56394 \\
5 & 74.18626 & 72.92092 & 74.68764 & 75.18142 & 76.08584 & 78.49957 & 56.92328 \\
6 & 75.70665 & 75.52148 & 79.21401 & 78.96517 & 77.09552 & 80.64976 & 61.89271 \\
7 & 77.67948 & 77.36803 & 81.04368 & 81.51931 & 82.09836 & 82.2375 & 66.7662 \\
8 & 78.74012 & 79.77062 & 82.88144 & 83.88144 & 85.0048 & 86.20664 & 71.57353 \\
\hline
\end{tabular}



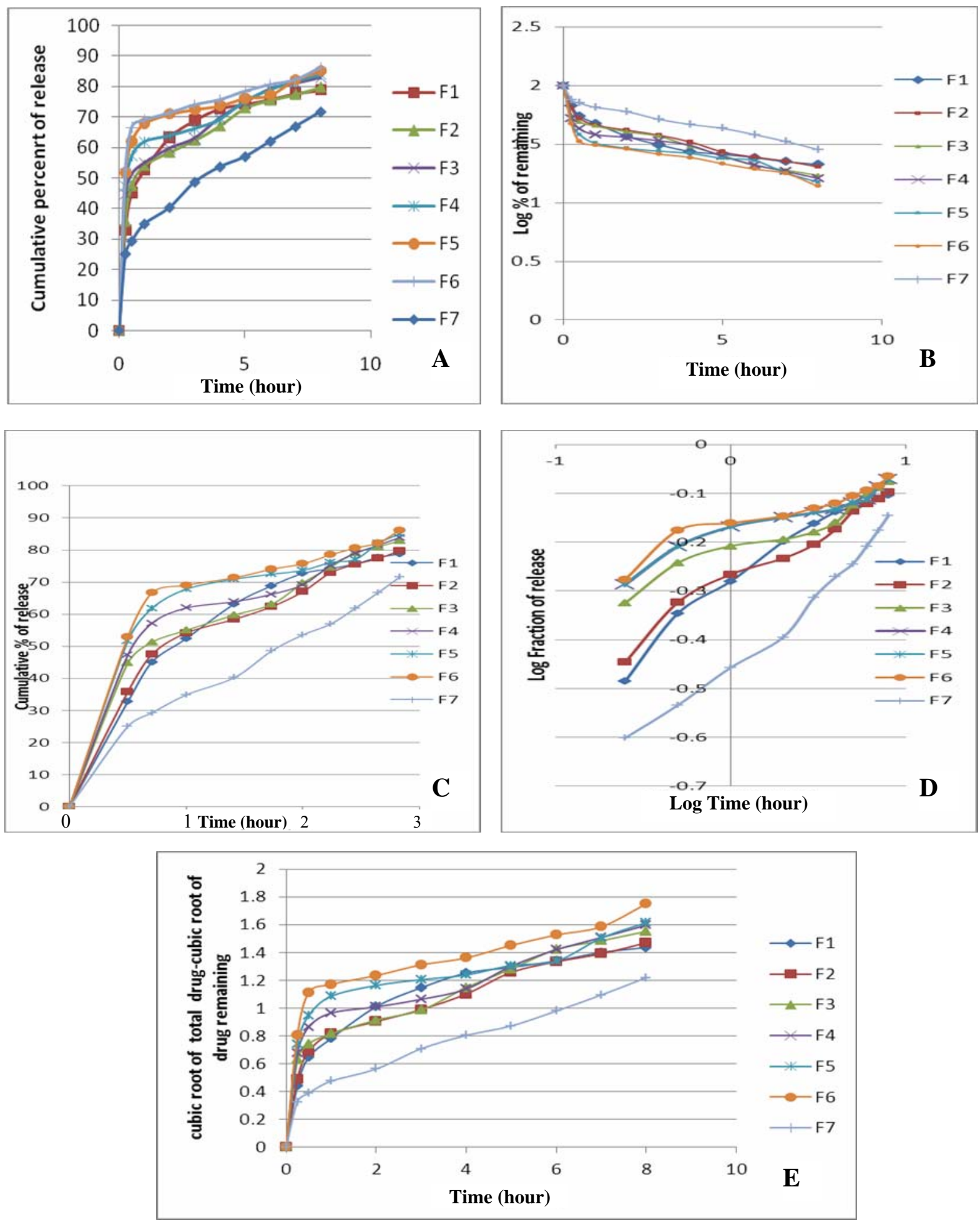

Figure 1. In vitro release kinetics of Naproxen from Ethyl Cellulose, Eudragit-RSPO and combined polymeric microspheres A. Zero order Plot B. First order Plot C. Higuchi plot D. Korsmeyer plot E. Hixson Crowell Plot. 
Table 3. Interpretation of release rate constants and R-squared values for different kinetics of ethyl cellulose, Eudragit RSPO and combined polymeric microsphere containing naproxen.

\begin{tabular}{cccccccccccc}
\hline Formulation & \multicolumn{2}{c}{ Zero order } & \multicolumn{2}{c}{ First Order } & \multicolumn{2}{c}{ Higuchi } & \multicolumn{3}{c}{ Korsmeyer-Peppas } & \multicolumn{3}{c}{ Hixson-Crowell } \\
\cline { 2 - 11 } & $\mathrm{K}_{0}$ & $\mathrm{R}^{2}$ & $\mathrm{~K}_{1}$ & $\mathrm{R}^{2}$ & $\mathrm{~K}_{\mathrm{h}}$ & $\mathrm{R}^{2}$ & $\mathrm{~N}$ & $\mathrm{~K}_{\mathrm{km}}$ & $\mathrm{R}^{2}$ & $\mathrm{~K}_{\mathrm{HC}}$ & $\mathrm{R}^{2}$ \\
\hline F-1 & 6.907 & 0.653 & -0.161 & 0.831 & 24.04 & 0.861 & 0.239 & 0.506 & 0.965 & 0.142 & 0.502 \\
F-2 & 6.731 & 0.677 & -0.159 & 0.879 & 23.04 & 0.863 & 0.211 & 0.514 & 0.974 & 0.139 & 0.82 \\
F-3 & 6.73 & 0.66 & -0.173 & 0.892 & 22.96 & 0.837 & 0.175 & 0.559 & 0.966 & 0.144 & 0.928 \\
F-4 & 6.223 & 0.576 & -0.166 & 0.836 & 21.74 & 0.766 & 0.145 & 0.597 & 0.945 & 0.136 & 0.758 \\
F-5 & 5.669 & 0.472 & -0.154 & 0.735 & 20.63 & 0.68 & 0.118 & 0.644 & 0.939 & 0.123 & 0.647 \\
F-6 & 5.661 & 0.452 & -0.158 & 0.729 & 20.72 & 0.661 & 0.112 & 0.665 & 0.913 & 0.132 & 0.635 \\
F-7 & 6.861 & 0.855 & -0.128 & 0.953 & 22.12 & 0.967 & 0.3 & 0.359 & 0.982 & 0.123 & 0.923 \\
\hline
\end{tabular}

Table 4. Zero order release profile of pure naproxen from ethyl cellulose, Eudragit RSPO and mixed polymeric (ethyl cellulose + Eudragit RSPO) microspheres in acidic media.

\begin{tabular}{cccccccc}
\hline \multirow{2}{*}{$\begin{array}{c}\text { Time } \\
\text { (hr) }\end{array}$} & F1 & F2 & F3 & F4 & F5 & F6 & F7 \\
\cline { 2 - 8 }$y$ & 0 & 0 & 0 & 0 & 0 & 0 & 0 \\
0.25 & 2.256878 & 2.530992 & 2.6545 & 2.89 & 3.15 & 3.454246 & 2.074272 \\
0.5 & 2.957595 & 3.449733 & 3.69854 & 3.98 & 4.15 & 4.473074 & 2.46486 \\
1 & 4.258472 & 4.660761 & 4.75 & 4.85 & 5.12 & 5.80873 & 3.672923 \\
1.5 & 6.025852 & 6.521542 & 6.84 & 6.86 & 7.45 & 9.949811 & 5.530782 \\
2 & 8.170392 & 8.484355 & 8.68 & 8.78 & 9.12 & 10.52843 & 6.939368 \\
\hline
\end{tabular}

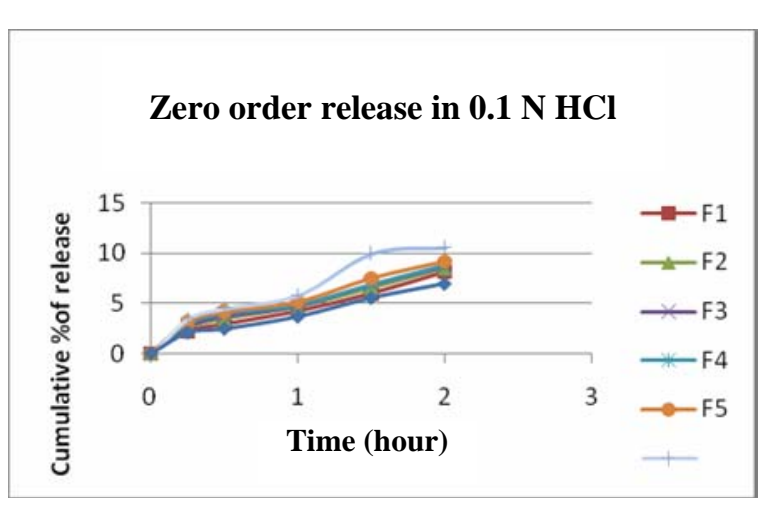

Figure 2. Zero order release of Naproxen from Ethyl Cellulose, Eudragit-RSPO and combined polymeric microspheres. release of Naproxen as obtained is $10.5284 \%$ and minimum is $2.0742727 \%$ in two hours from the batch F6 and F7, respectively. It showed that the swelling and pore formation of Ethyl Cellulose and Eudragit RS PO were very small in acidic media.

\section{Surface morphology study}

Effect of ethyl cellulose on the surface morphology of batch F6 ( $50 \%$ naproxen $+50 \%$ ethyl cellulose). The surface of the microsphere was not smooth. There were so many pores present on the surface. It
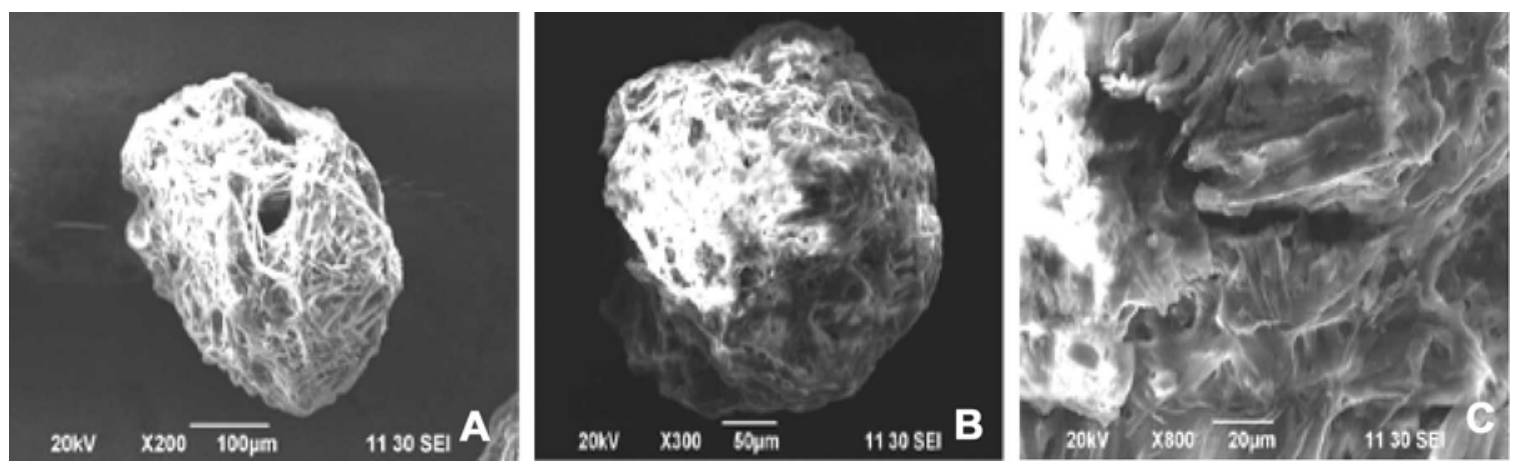

Figure 3. Effect of Ethyl Cellulose on the surface morphology of the microspheres. A. Before dissolution studies, B. Dissolution after 1 hour at x300 magnification, C. Dissolution after 1 hour at x 800 magnification. 
facilitated the entry of the dissolution media and quick wetting. This was one of the reasons of burst release of Naproxen from the microsphere. The uneven texture revealed that the surface of the microsphere contained moisture. The presence of moisture caused weakening of the matrix. Relatively faster release of drug caused the slow breakdown of the matrix. Careful examination of the SEM picture (Fig. 3B) of the same batch, after 1 hour of dissolution, clearly showed that the matrix was not in the former shape after 1 hour of dissolution. The shape of the matrix distorted which is due to the rapid release of drug and there were so many channels or pores (Fig 3C). Presence of moisture was also responsible for weakening of the matrix.
Effect of ethyl cellulose and Eudragit RSPO on the surface morphology of batch F2 (50\% naproxen $+10 \%$ ethyl cellulose $+40 \%$ Eudragit RSPO). The surface of this microsphere was more rigid and less porous compared to the batch F6. This was due to increased amount of Eudragit RSPO. The rigidity of the polymeric matrix increased with the increase of the amount of Eudragit RS PO. The SEM picture of batch F2 (Fig. 4C) revealed that the number of pores produced was less than the batch F6 (Fig. 3C) after 1 hour of dissolution. The amount of burst release decreased with the increased amount of Eudragit RSPO. Uneven texture of the surface was also seen which was due to the presence of moisture. The shape of the matrix was also distorted after 1 hour of dissolution
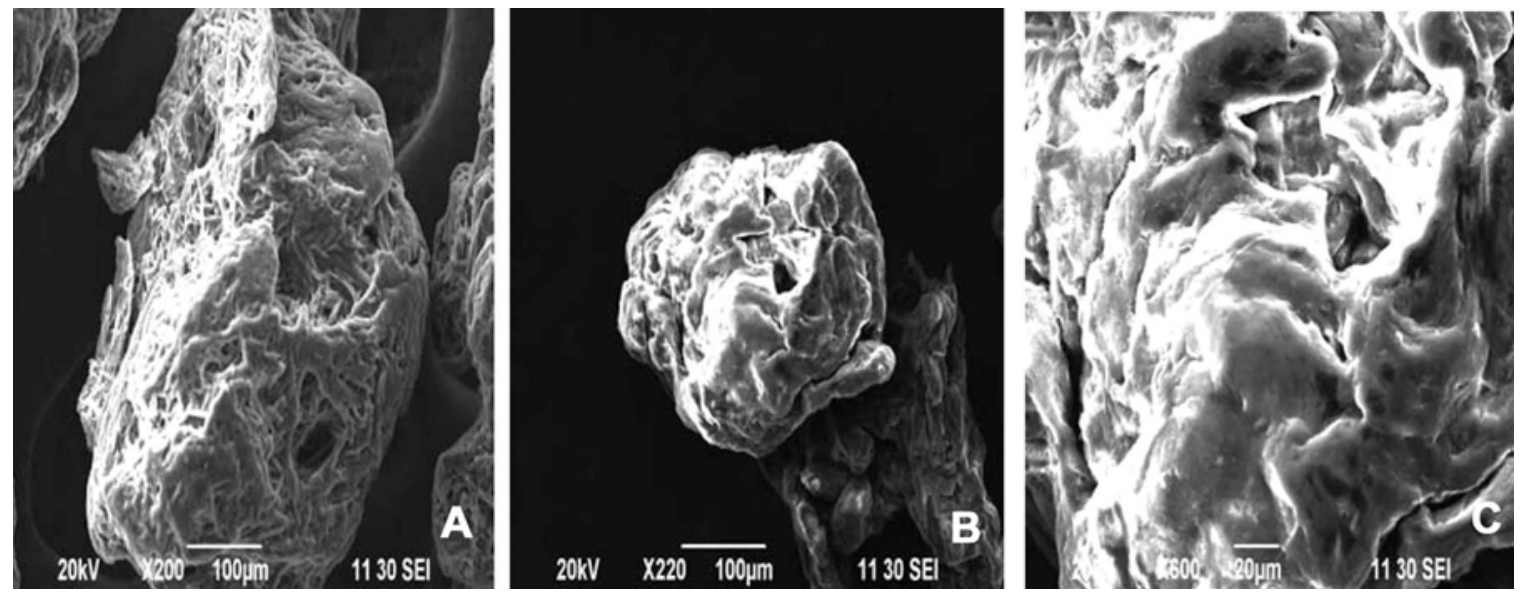

Figure 4. Effect of Ethyl Cellulose and Eudragit RSPO on the surface morphology on batch F2 (50\% Naproxen+10\% Ethyl Cellulose $+40 \%$ Eudragit RSPO). A. Before dissolution studies, B. Dissolution after 1 hour at x220 magnification, C. Dissolution after 1 hour at x600 magnification

\section{Change of the surface morphology with the} change of polymers ratio. Microsphere became more rigid and less porous with the increasing amount of Eudragit RSPO. The smoothness of the microsphere was found to increase with the increased amount of Eudragit RSPO. Here highest rigid structured batch of microsphere is F1 $(50 \%$ Naproxen $+5 \%$ Ethyl Cellulose $+45 \%$ Eudragit RSPO), Fig. 3A; and most porous structured batch of microsphere is F6 $(50 \%$ Naproxen $+50 \%$ Ethyl Cellulose), Fig. 3B.

\section{Compatibility Study}

Fourier transform infrared spectrometric (FTIR) study to determine compatibility. The peak for the prominant functional groups of Naproxen were also found in the FTIR spectra of Naproxen microsphere indicated successful entrapment of Naproxen within microspheres (Table 5).

According to chemical structure of Naproxen, it contains aromatic ring, carboxyl group, ether group (Alkyl-O and Aryl-O). 

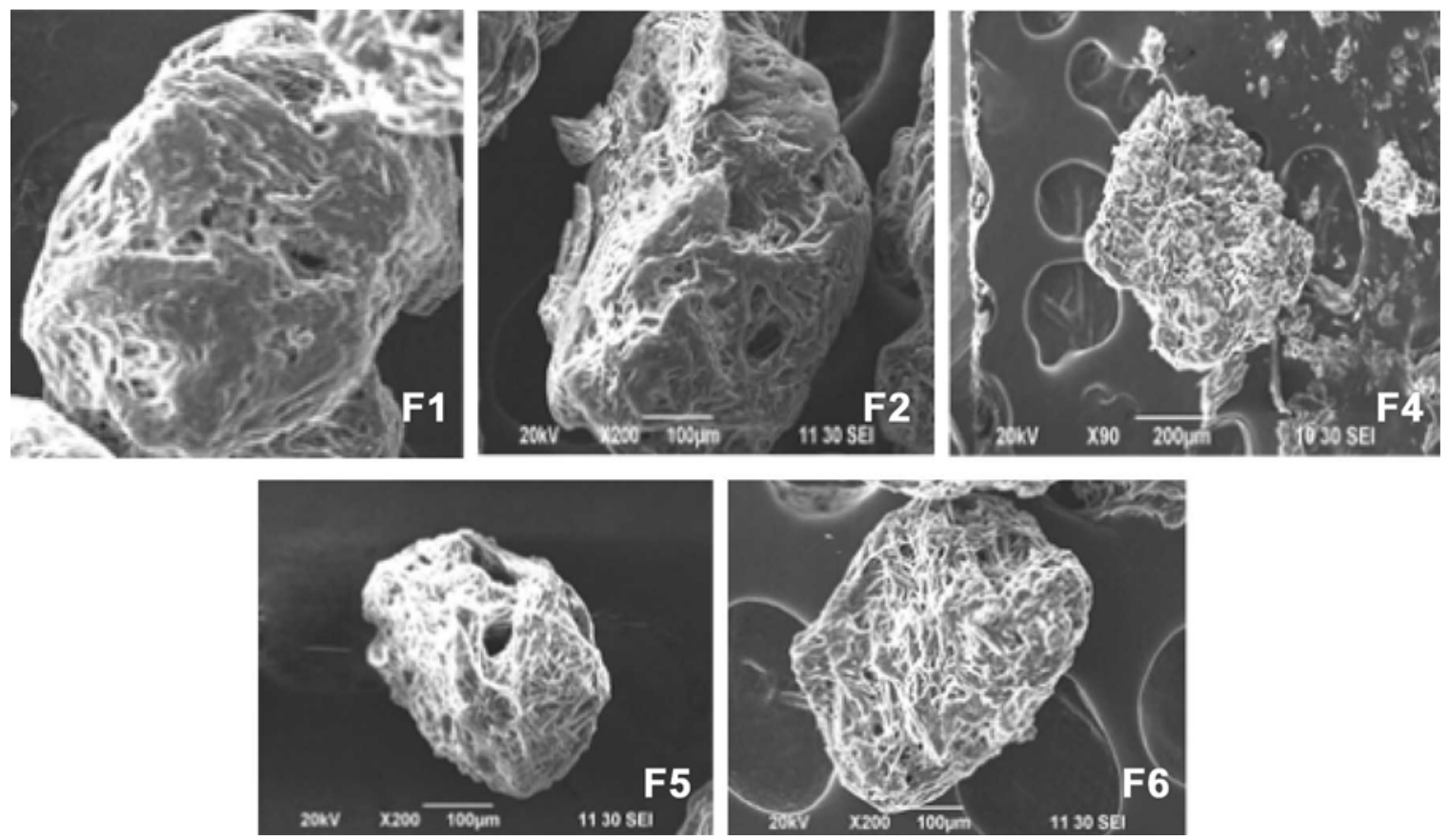

Figure 5. SEM picture of batch F1(A), F2(B), F4(C), F5(D) and F6(E)<smiles>COc1ccc2cc([C@@H](C)C(=O)O)ccc2c1</smiles>

Figure 6. Chemical structure of Naproxen

Table 5. Fourier Transform Infrared Spectroscopic data of pure Naproxen and prepared microspheres.

\begin{tabular}{|c|c|c|c|c|c|c|c|c|}
\hline $\begin{array}{l}\text { Functiona } \\
1 \text { Gorup }\end{array}$ & & $\begin{array}{c}\text { Standard } \\
\text { Peak Region } \\
\left(\mathrm{cm}^{-1}\right)\end{array}$ & $\begin{array}{c}\text { FTIR Spectra } \\
\text { of Pure } \\
\text { Naproxen } \\
\left(\mathrm{cm}^{-1}\right)\end{array}$ & $\begin{array}{c}\text { FTIR } \\
\text { Spectra of } \\
\text { F7 } \\
\left(\mathrm{cm}^{-1}\right)\end{array}$ & $\begin{array}{c}\text { FTIR } \\
\text { Spectra of F6 } \\
\left(\mathrm{cm}^{-1}\right)\end{array}$ & $\begin{array}{c}\text { FTIR } \\
\text { Spectra of F5 } \\
\left(\mathrm{cm}^{-1}\right)\end{array}$ & $\begin{array}{c}\text { FTIR } \\
\text { Spectra of } \\
\text { F4 } \\
\left(\mathrm{cm}^{-1}\right)\end{array}$ & $\begin{array}{c}\text { FTIR } \\
\text { Spectra of } \\
\text { F2 } \\
\left(\mathrm{cm}^{-1}\right)\end{array}$ \\
\hline \multirow{3}{*}{$\begin{array}{l}\text { Carboxyl } \\
\text { Group } \\
(-\mathrm{COOH})\end{array}$} & O-H Strech & $3500-2400$ & 3214 & 3443.96 & 3430.46 & 3437.21 & 3433.35 & 3431.42 \\
\hline & $\mathrm{C}=\mathrm{O}$ sterch & $1730-1700$ & 1227.71 & 1729.21 & 1728.25 & 1736.93 & 1731.14 & 1728.25 \\
\hline & C-O strech & $1320-1210$ & 1729.210 & 1304.91 & 1228.68 & 1228.68 & 1228.68 & 1228.68 \\
\hline $\begin{array}{l}\text { Aromatic } \\
\text { Ring }\end{array}$ & $\begin{array}{l}\mathrm{C}=\mathrm{C}-\mathrm{C}^{\mathrm{a}} \\
\text { strech }\end{array}$ & $\begin{array}{l}1615-1580 \\
\text { and } \\
1510-1450\end{array}$ & $\begin{array}{l}1604.8 \text { and } \\
1510-1450\end{array}$ & $\begin{array}{c}1604.80 \\
\text { and } \\
1453.39\end{array}$ & $\begin{array}{c}1605.77 \\
\text { and } \\
1453.39\end{array}$ & $\begin{array}{l}1604.80 \\
\text { and } \\
1467.65\end{array}$ & $\begin{array}{c}1604.80 \\
\text { and } \\
1466.89\end{array}$ & $\begin{array}{c}1604.80 \\
\text { and } \\
1458.21\end{array}$ \\
\hline \multirow[t]{2}{*}{ Ether } & $\begin{array}{l}\text { Aryl-O } \\
\text { stretch }\end{array}$ & $1270-1230$ & 1264.36 & 1264.36 & 1265.32 & 1264.36 & 1264.36 & 1265.32 \\
\hline & $\begin{array}{l}\text { Alkyl C-O } \\
\text { stretch }\end{array}$ & $1150-1050$ & 1090.76 & 1029.04 & 1091.73 & 1119.70 & 1114.87 & 1029.04 \\
\hline
\end{tabular}

Differential Scanning Calorimetric studies. The pure drug (Naproxen), the polymers, the physical mixture of Naproxen and polymers and the prepared microsphere were subjected to DSC study. The endothermic melting peak was found at $157.35^{\circ}$. This melting peak was also found in the DSC thermogram of the physical mixture of Naproxen and polymer 

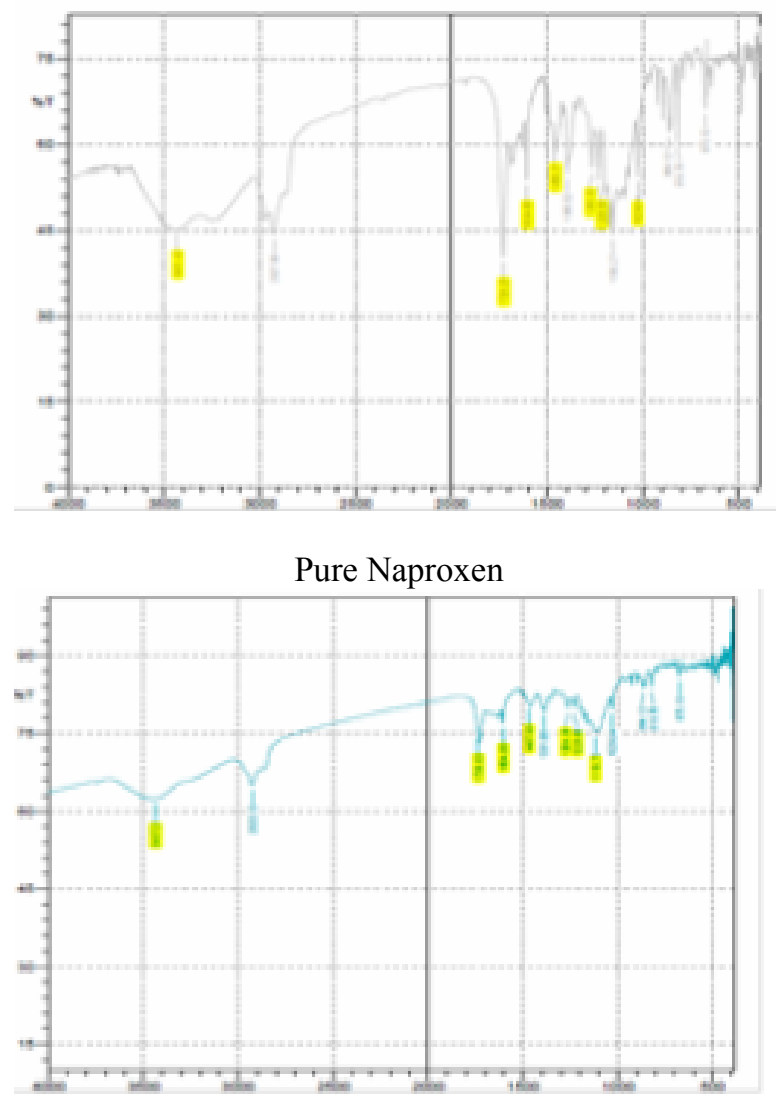

Batch F4

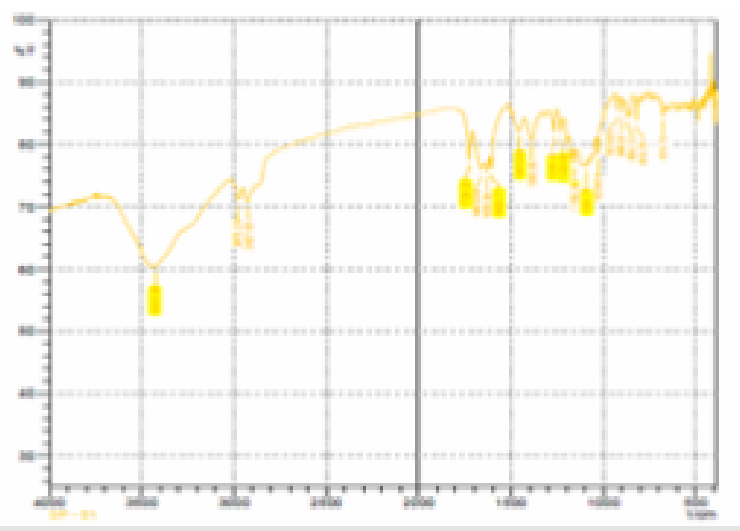

Batch F6

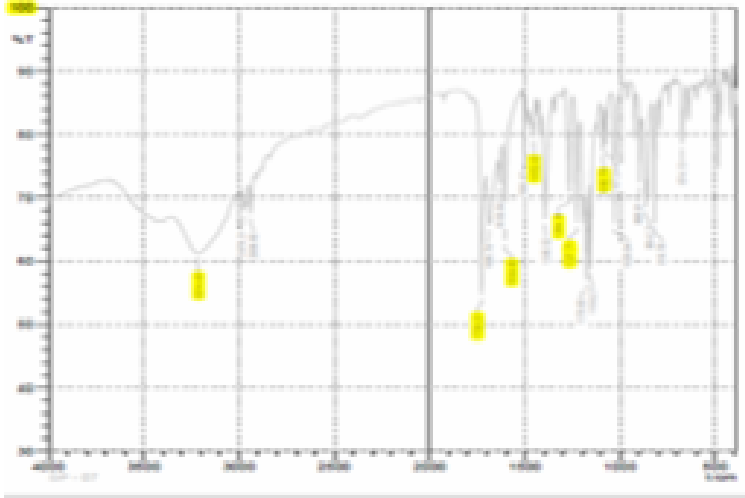

Batch F2

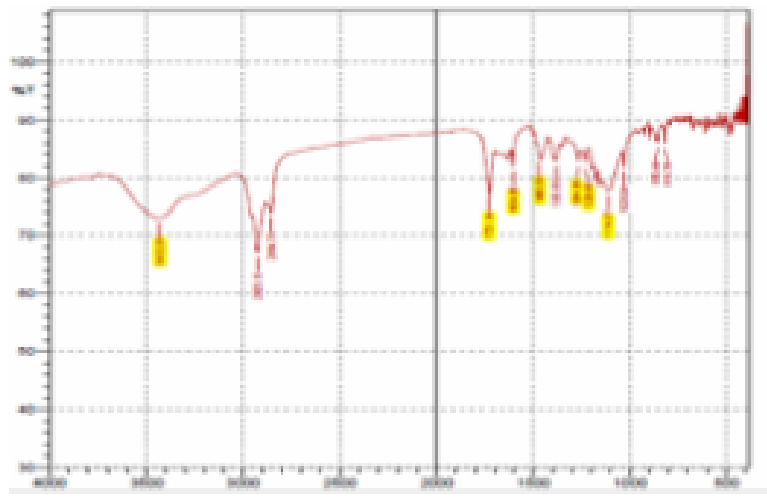

Batch F5

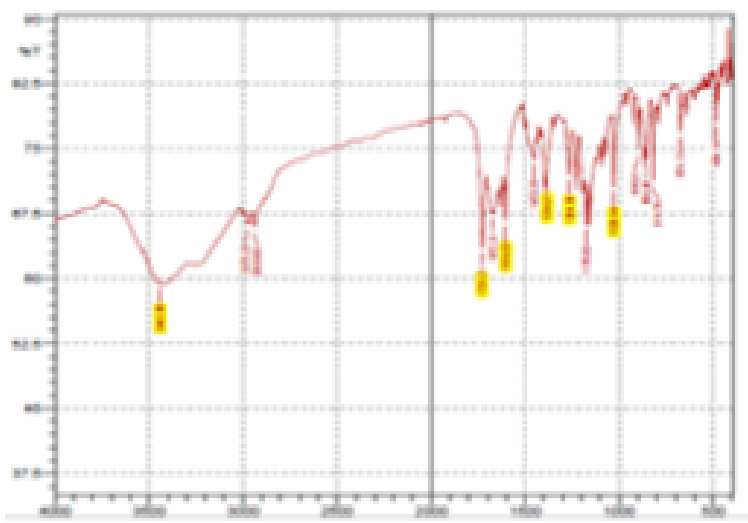

Batch F7

Figure 7. FTIR spectrum of pure Naproxen of different batches.

although with slight shifting but remaining within a range. The peak was absent in the DSC thermogram of the prepared microsphere.

During microsphere formation, the polymers inhibited the recrysrtallisation of the drug. The disappearance of the endothermic peak corresponding to the encapsulated drug melting point, indicates the dispersion of drug in the polymers as solid solution or as a metastable molecular dispersion. ${ }^{9}$ 


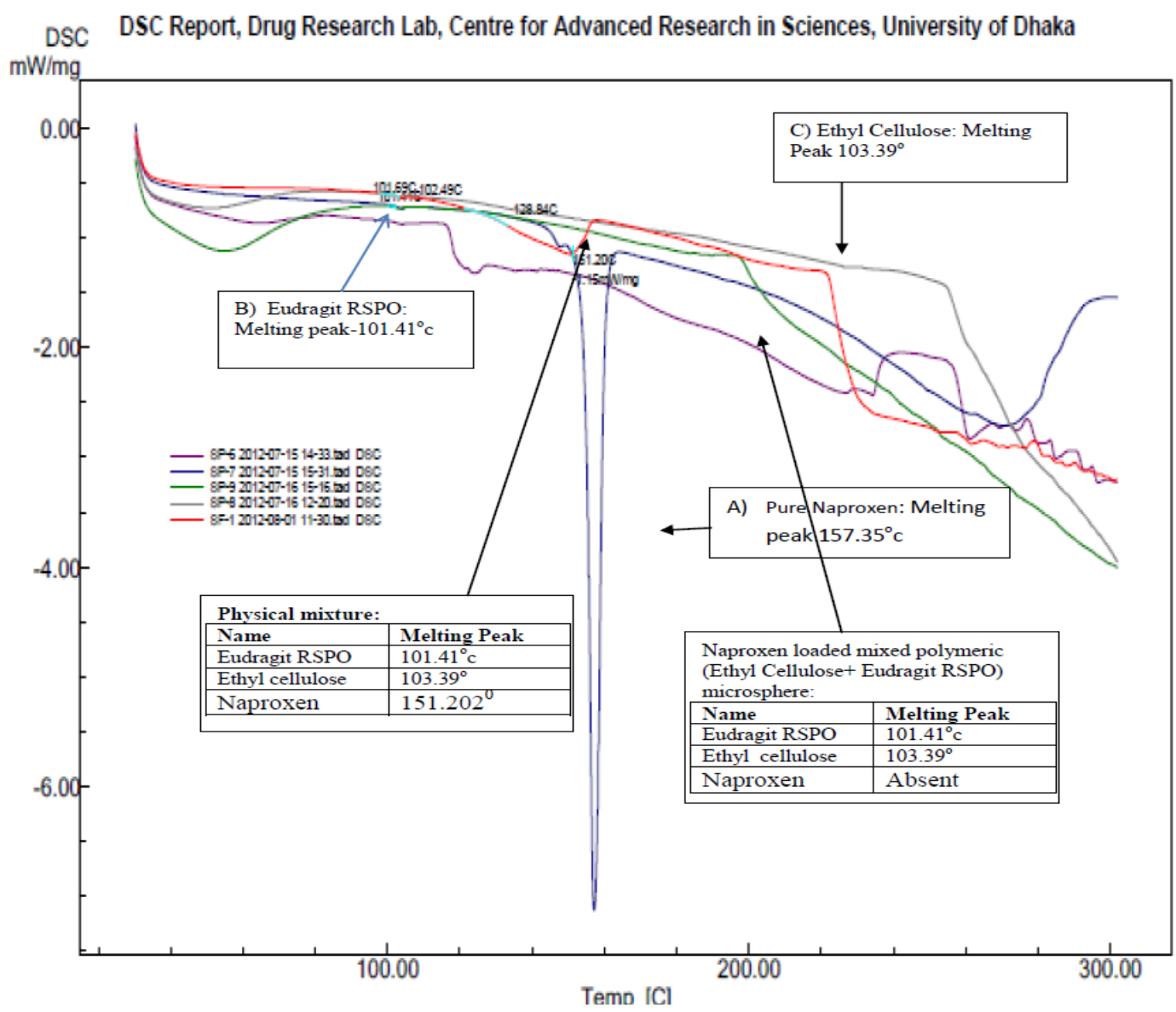

Figure 8. DSC Thermogram of pure Naproxen, Ethyl Cellulose, Eudragit RSPO, their Physical Mixture and Prepared Microsphere (batch F5).

\section{CONCLUSION}

This study was performed with a view to establishing the Ethyl Cellulose (14 cps) and Eudragit RSPO as premium polymer for microencapsulation technology and also for establishing the emulsion solvent evaporation as a technique for microsphere formation. Naproxen may be an excellent candidate for consideration in drug delivery system as sustained release dosage form. Microsphere of the mentioned polymers can be used as a vehicle to modulate the drug release for a sustained activity for 6 to 8 hours.

Naproxen loaded microspheres were formed by emulsion solvent evaporation technique which was found to be reproducible and also may be ideal method to prepare the microsphere in large scale. In this experiment, other factors such as types of solvent, rpm, stirring time were kept constant.

Microsphere was formed by using two types of polymers Ethyl Cellulose (14 cps) and Eudragit RSPO. Naproxen was loaded within the Ethyl Cellulose, Eudragit RSPO and their combination matrix. In case of combination different polymer ratios were used. Drug loading was kept constant.

Dissolution study was performed in phosphate buffer ( $\mathrm{pH}$ 7.4) for 8 hours and also in $0.1 \mathrm{~N} \mathrm{HCl}$ for 2 hours. The results showed sustained release in case of phosphate buffer and very small release in acidic media. The reduced release in acidic media clearly proved that both the polymers are capable of preventing Naproxen induced gastric irritation. It can be cost effective as no extra enteric coating polymers 
were used. The release kinetics for all the batches were best fitted to Korsmeyer-Peppas model, and Fickian (class 1) diffusion was prominent. (Mechanism of transport).

The SEM study was performed to characterize the surface morphology of the prepared microsphere. The SEM reports depicted that the particles' surface morphology was drastically changes as the ratio between the polymer changes. Two of seven batches were subjected to SEM study dissolution after 1 hour. From the study report, it was seen that there were pores or channels produced within the polymeric matrix.

FTIR showed a successful formulation technique of preparing microsphere as showing the presence of the drug within the microsphere.

Thermal analysis by DSC was also performed for pure drug (Naproxen), pure polymers (Ethyl Cellulose and Eudragit RS PO, physical mixture of drug and polymers, and the prepared microspheres. In the physical mixture the endothermic melting peak of Naproxen was found with slight shifting but remained within an acceptable range but the endothermic melting peak of Naproxen disappeared in the thermogram for all the prepared batches. Both the individual polymer and their combination inhibited the recrysrtallisation of Naproxen.

Particle size analysis was done by particle size analyzer based on refractive index. Reports of particle size analysis clearly showed that the size of the particles was within in the range $(1-1000 \mu \mathrm{m})$. The mean particle size increased with the increase of Eudragit RSPO concentration.

Though, pellets and tablets are the most diversified drug delivery devices now a days, they have some drawbacks of being time consuming, costly and having multistep processes of preparation. On the other hand microspheres produced in this method offer more opportunities to modulate the drug release behavior minimizing the degree of drawbacks associated with the pellets. But the limitation of emulsion solvent evaporation technique must be kept in mind. Compatible polymers and solvents selection are challenging tasks of this method. If the formulation and process variables are optimized successfully, the method of microsphere formation used in this study may be an ideal means of drug delivery device.

\section{REFERENCES}

1. Wan, LS. and Chui, WK. 1995. Deviation of the ratio of drugs in a two component mixture encapsulated in cellulose phthalate microspheres. J Microencap. 12, 417-23.

2. Yamuda, T., Onishi, H. and Machida, Y. 2001. Sustained release ketoprofenmicroparticles with ethyl cellulose and carboxymethyl ethyl cellulose. J. Controlled Release 75, 271-282.

3. Bolourtchian, N., Karimi, K. and Aboofazeli, R. 2005. Preparation and characterization of Ibuprofen microspheres. J. Microencap. 22, 529-538.

4. Haznedar, S. and Dortunç, B. 2004. Preparation and in vitro evaluation of Eudragit microspheres containing acetazolamide. Int. J. Pharm. 269, 131-140

5. Zaghloul, AA, Faltinek, J, Vaithiyalingam, SR, Reddy, IK and Khan, MA. 2001. Screening of process and formulation variables for the preparation of extended release tablets of Naproxen-Eudragit microspheres. Pharmazie 56, 321-4.

6. Korsmeyer, RW.,Gurny, R., Doelker, EM., Buri, P. and Peppas, N.A. 1983. Mechanism of solute release from porous hydrophilic polymers. International J. Pharmaceutics 15, 25-35.

7. Higuchi, T. 1963. Mechanism of sustained action medication, theoretical analysis of rate of release of solid drugs dispersed in solid matrices. J. Pharm. Sci. 52, 1145-1149.

8. Horoz, B., Kiliic, M., Arslan, N. and Baykara, Y T. 2004. Effect of different dispersing agents on the characteristics of Eudragit microspheres prepared by a solvent evaporation method. J. Microencap. 21, 191-202.

9. Mello, V.A. and Ricci, R. 2011. Encapsulation of Naproxen in nanosphered system: structural characterization and in vitro release studies Vol. 34 no. 6. 